\title{
Perfil de ácidos graxos e qualidade da carne de vacas de descarte terminadas em confinamento recebendo dietas com ou sem adição de monensina
}

\author{
Fatty acid profile and meat quality of cull cows feedlot finished receiving diet with or \\ without monensin \\ Fernando Kuss $^{1}$ João Restle ${ }^{2}$ Francisco Deschamps $^{3}$ Gilberto Vilmar Kosloski ${ }^{4}$ \\ Angélica Pereira dos Santos ${ }^{5}$ Luis Fernando Glasenapp de Menezes ${ }^{6}$ \\ Jarlei Fiamoncini ${ }^{7}$
}

\section{RESUMO}

Foram avaliados o perfil dos ácidos graxos da gordura intramuscular e a qualidade da carne de vacas de descarte terminadas em confinamento recebendo dietas sem ou com monensina sódica (200mg animal ${ }^{-1}$ dia $^{-1}$ ). A dieta continha 12,5\% de proteína bruta e 2,99Mcal de energia digestível $\mathrm{kg}^{-1}$ de matéria seca, composta de $48 \%$ de volumoso (silagem de milho) e 52\% de concentrado. A presença de monensina não teve efeito significativo sobre a cor, a textura e o marmoreio, apresentando valores médios de 3,55; 3,29 e 6,38 pontos, respectivamente. Quanto às características sensoriais, a carne dos animais alimentados com monensina demonstra ser menos palatável $(P<0,10)$. A inclusão de monensina ocasionou o aumento $(P<0,10)$ da participação de ácidos graxos saturados e a redução dos insaturados na gordura intramuscular do Longissimus dorsi. Entre os ácidos graxos saturados, o uso de monensina aumentou a proporção de heptadecanóico (17:0) e, entre os insaturados, aumentou a proporção do isômero trans (C18:1 n9t) e diminuiu o cis (C18:1 n9c) do oléico. A proporção total de monoinsaturados também reduziu com a inclusão da monensina $(P<0,10)$. A inclusão de monensina diminuiu a qualidade da carne das vacas por diminuir sua palatabilidade. Quanto ao perfil de ácidos graxos totais, a monensina proporciona maior participação de ácidos graxos saturados em detrimento dos insaturados na gordura intramuscular do músculo Longissimus dorsi.

Palavras-chave: composição lipídica, fêmeas, gordura intramuscular, ionóforo, palatabilidade.

\begin{abstract}
The marbling fatty acid profile and the meat quality of cull cows feedlot finished receiving diets without or with sodic monensin $\left(200 \mathrm{mg}_{\text {animal }}{ }^{-1}\right.$ day $\left.^{-1}\right)$ were evaluated. The diet contained $12.5 \%$ of crude protein and 2.99 Mcal of digestible energy $\mathrm{kg}^{-1}$ of dry matter, composed of $48 \%$ of roughage (corn silage) and 52\% of concentrate. The monensin presence didn't have significant effect on the color, texture and marbling, presenting medium values of $3.55,3.29$ and 6.38 points, respectively. Concerning the sensorial characteristics, the meat of the animals fed with monensin it demonstrated to be less palatable $(P<.10)$. The monensin inclusion caused the increase $(P<.10)$ of the participation of saturated fatty acids and reduction of the unsaturated in the fat intramuscular of the Longissimus dorsi. Among the fatty acids saturated, the use of monensin increased heptadecanóico (17:0) proportion and, among the unsaturated group, the trans isomer (C18:1 n9t) increased, and the cis isomer of oleate (C18:1 n9c) decreased $(P<.10)$. The monounsaturated fatty acids proportion was reduced by monensin inclusion $(P<.10)$. Monensin addition decreased the meat quality by decrease its palatability of the meat of cull cows. As regards the profile of fatty acids total, the monensin provides larger participation of saturated fatty acid in detriments to the unsaturated in the fat marbling of the muscle Longissimus dorsi.
\end{abstract}

Key words: composition fat, females, intramuscular fat, ionophore, palatability.

\footnotetext{
${ }^{1}$ Programa de Pós-graduação em Zootecnia, Universidade Federal do Rio Grande do Sul (UFRGS). E-mail: fernandokuss@ig.com.br. Autor para correspondência.

${ }^{2}$ Departamento de Produção Animal, Escola de Veterinária da Universidade Federal de Goiás (UFG), Goiânia, Goiás, Brasil.

${ }^{3}$ Empresa de Pesquisa Agropecuária e Extensão (EPAGRI), Universidade do Vale do Itajaí (UNIVALI), Itajaí, SC, Brasil.

${ }^{4}$ Departamento de Zootecnia da Universidade Federal de Santa Maria (UFSM), Santa Maria, RS, Brasil.

${ }^{5}$ Programa de Pós-graduação em Zootecnia, UFRGS, Porto Alegre, RS, Brasil.

${ }^{6}$ Programa de Pós-graduação em Zootecnia, UFSM, Santa Maria, RS, Brasil.

${ }^{7}$ Curso de Biologia/Biotecnologia da UNIVALI, Itajaí, SC, Brasil.
} 


\section{INTRODUÇÃO}

A monensina sódica é um aditivo largamente utilizado na alimentação de bovinos na fase de terminação em confinamento com a finalidade de melhorar a eficiência alimentar. Esta forma de ionóforo aumenta a produção de ácido propiônico no rúmen, resultando em decréscimo na proporção do ácido acético. Esta situação é resultado da ação seletiva na população microbiana, afetando negativamente as bactérias gram-positivas, que são produtoras primárias de acetato e butirato. Outra ação importante da monensina é a redução da degradação de proteínas e peptídeos pelos microorganismos ruminais, aumentando o fluxo de aminoácidos dietéticos que chegam ao intestino delgado (NRC, 1996). No entanto, possíveis efeitos sobre a qualidade, assim como sobre a composição dos ácidos graxos da carne de animais alimentados com monensina, não estão ainda bem estabelecidos.

Além do teor de gordura, a avaliação do perfil de ácidos graxos de cadeia longa presentes na carne vem sendo incrementadamente incluída como tema de pesquisa em bovinos de corte. Embora a mídia divulgue que normalmente a gordura animal está associada negativamente a doenças cardiovasculares e cancerígenas, estudos recentes têm demonstrado que o consumo moderado de gordura de origem animal pode prevenir o desenvolvimento dessas mesmas doenças. Alguns ácidos graxos, particularmente os polinsaturados, servem como matéria-prima para substâncias que regulam a imunidade, a coagulação sanguínea, a contração dos vasos e a pressão arterial (SIMOPOULOS, 1999). Além disso, os ácidos graxos insaturados, especialmente aqueles com mais de duas ligações duplas, normalmente são rapidamente oxidados e, desta forma, influenciam negativamente sobre a vida de prateleira da carne (rancidez e alteração da cor) e também sobre a sua palatabilidade (WOOD et al., 2003). Já WALDMAN et al. (1968), por sua vez, relatam correlação negativa entre a suculência e os teores dos ácidos graxos merístico (14:0) e palmítico (C16:0), e positiva com a proporção de ácidos graxos insaturados:saturados da carne.

Trabalhos recentes demonstram que a taxa de hidrólise dos triglicerídeos e de biohidrogenação dos ácidos graxos foram reduzidas com a adição de monensina na dieta (VAN NEVEL \& DEMEYER, 1995; FELLNER et al., 1997). MENEZES et al. (2006), por sua vez, verificaram que a adição de níveis de monensina sódica na dieta de novilhos terminados em confinamento reduziu a palatabilidade e a suculência, bem como alterou a composição dos ácidos graxos da carne. Porém, RESTLE et al. (2000) não observaram alterações sobre as características sensoriais da carne com a presença da monensina na dieta.

Considerando que, no Brasil, aproximadamente $50 \%$ dos animais abatidos são fêmeas (ANUALPEC, 2005), torna-se necessário gerar informações mais detalhadas relacionadas aos aspectos qualitativos da carne desta categoria. Neste contexto, esta pesquisa foi conduzida com o intuito de avaliar o perfil de ácidos graxos e a qualidade da carne de vacas de descarte, mestiças Charolês-Nelore, terminadas em confinamento com ou sem a adição de monensina sódica à dieta.

\section{MATERIAL E MÉTODOS}

O estudo foi conduzido no Setor de Bovinocultura de Corte do Departamento de Zootecnia da Universidade Federal de Santa Maria (UFSM). Para este estudo foram utilizadas 24 vacas de descarte mestiças Charolês x Nelore, as quais, ao início do período experimental, apresentavam em média 8,5 anos de idade, $388,6 \mathrm{~kg}$ de peso vivo e 2,35 pontos de escore da condição corporal (escala de 1 a 5). Os animais permaneceram 92 dias em confinamento, recebendo dietas sem ou com (200mg animal $\left.{ }^{-1} \mathrm{dia}^{-1}\right)$ monensina sódica. A dieta continha $12,5 \%$ de proteína bruta e 2,99Mcal de energia digestível $\mathrm{kg}^{-1}$ de matéria seca (MS), composta de $48 \%$ de volumoso (silagem de milho) e $52 \%$ de concentrado ( $92 \%$ de farelo de trigo; $6,8 \%$ de calcário calcítico e $0,6 \%$ de sal comum, com base na MS).

Os animais foram abatidos em frigorífico comercial, obedecendo ao fluxo de abate normal do estabelecimento. Por ocasião do abate, as carcaças foram identificadas e mantidas em câmara fria por um período de $24 \mathrm{~h}$ à temperatura de $0^{\circ} \mathrm{C}$. Decorrido este período, na meia carcaça direita, foi realizado um corte horizontal entre a $12^{\mathrm{a}}$ e a $13^{\mathrm{a}}$ costela com o intuito de expor o músculo Longissumus dorsi para a aferição do grau de marmorização (1 a $3=$ traços, a 16 a $18=$ abundante) relacionada à gordura intramuscular. Além disso, procurou-se verificar a textura $(1=$ muito grosseira a $5=$ muito fina) por meio da observação da granulometria das fibras musculares e da coloração ( $1=$ escura a $5=$ vermelho vivo), avaliada após 30 minutos de exposição do corte ao ar (MÜLLER, 1987).

Para a aferição das características organolépticas da carne e do perfil de ácidos graxos, ainda na meia carcaça direita, foi extraída uma amostra do músculo Longissimus dorsi, correspondendo à porção da 10-11-12 $2^{\mathrm{a}}$ costelas, a qual foi embalada em lâmina de plástico e papel pardo, identificada e 
imediatamente congelada à temperatura de $-18^{\circ} \mathrm{C}$, durante 60 dias. Após este período, foram retirados quatro bifes com espessura de $2,5 \mathrm{~cm}$ da porção cranial de amostra ainda congelada, sendo dois bifes postos a descongelar em refrigerador doméstico por 24h. Depois de descongelados, os bifes foram assados em forno até atingir temperatura interna de $70^{\circ} \mathrm{C}$. Um desses bifes foi pesado congelado, descongelado e após o cozimento, para as avaliações do percentual de perdas ao descongelamento e à cocção, sendo o mesmo bife utilizado na avaliação da resistência das fibras ao corte, por intermédio do aparelho Warner-Bratzler Shear (WBS), cujo resultado foi a média aritmética através de seis leituras por bife (MÜLLER, 1987). O outro bife cozido foi destinado às avaliações da maciez, da palatabilidade e da suculência $(1=$ extremamente dura, sem sabor ou sem suculência; a $9=$ extremamente saborosa ou extremamente suculenta; respectivamente), por intermédio de um painel de cinco degustadores treinados (MÜLLER, 1987).

O terceiro bife, ainda congelado, foi novamente embalado, identificado e armazenado novamente no freezer, para posterior determinação do teor de lipídios totais (TERRA \& BRUM, 1988) e de nitrogênio pelo método Kjeldahl. O teor de proteína bruta foi calculado a partir do teor de nitrogênio multiplicado por 6,25 .

$\mathrm{O}$ quarto bife foi secado em estufa de ventilação forçada $\left(55^{\circ} \mathrm{C}\right)$, moído (peneira de $1 \mathrm{~mm}$ ), identificado e armazenado para posteriores análises. Nesta amostra foi feita a extração dos lipídeos utilizando-se o método modificado de FOLCH et al. (1957). Cerca de 0,5g de cada amostra foi colocada em um tubo de vidro e adicionados $10 \mathrm{~mL}$ de clorofórmio/ metanol (2:1). Após 24 horas, foram adicionados $10 \mathrm{~mL}$ de água destilada e os tubos centrifugados a $500 \times \mathrm{g}$ por 5 minutos para separar as fases. Transferiu-se a fase orgânica (clorofórmio) para tubos de ensaio com tampa rosqueável, sendo deixada em banho-maria a $40^{\circ} \mathrm{C}$, sob fluxo de ar comprimido, até restarem apenas os lipídios no fundo do tubo.

Para derivatização dos ácidos graxos, foram adicionados no tubo com os lipídios $500 \mathrm{~mL}$ de $\mathrm{KOH}$ $0,4 \mathrm{M}$ em metanol, deixando-se em banho-maria $\left(60^{\circ} \mathrm{C}\right.$ por 2 horas). Posteriormente, após resfriados sob temperatura ambiente, foram adicionados $1,5 \mathrm{~mL}$ de $\mathrm{H}_{2} \mathrm{SO}_{4}(1 \mathrm{M})$ em metanol. Os tubos foram deixados novamente em banho-maria a $60^{\circ} \mathrm{C}$ por mais 2 horas. A seguir, foram resfriados e adicionados $2 \mathrm{~mL}$ de $\mathrm{n}$-hexano para recuperar os derivados. Os ésteres metílicos de ácidos graxos foram mantidos a $-18^{\circ} \mathrm{C}$ até o momento de sua análise.

A determinação foi feita em cromatógrafo a gás, equipado com o detector de ionização de chama
(FID) e coluna capilar Supelco SP2340 (60m x 0,25mm x $0,2 \mu \mathrm{m})$. As temperaturas do detector e do injetor foram $260^{\circ} \mathrm{C}$ e $240^{\circ} \mathrm{C}$, respectivamente. A programação de aquecimento da coluna foi iniciada com $140^{\circ} \mathrm{C}$ por 5 minutos e aumento gradual de $4^{\circ} \mathrm{C}$ por minuto até a temperatura final de $240^{\circ} \mathrm{C}$, permanecendo assim por $5 \mathrm{~min}$. O fluxo de gás de arraste $(\mathrm{H} 2)$ foi de $17 \mathrm{~mL} \mathrm{~min}^{-1}$. O volume de injeção foi de $0,5 \mu \mathrm{L}$ com razão de split de 1:100. A identificação dos picos, assim como a quantificação, foi feita pela comparação dos tempos de retenção e da área dos picos das amostras com as de padrões de ésteres metílicos de ácidos graxos (Supelco 37 components FAMEs Mix, ref. 47885-U).

O delineamento experimental utilizado foi o inteiramente casualizado (dois tratamentos com doze repetições cada), sendo os dados submetidos a análise de variância e as médias comparadas pelo teste F (Pdiff). Foi também realizada análise de correlação de Pearson entre as variáveis dependentes. As análises foram realizadas utilizando-se o programa estatístico SAS (1997)

\section{RESULTADOS E DISCUSSÃO}

As variáveis independentes cor, textura e marmoreio da carne são demonstradas na tabela 1 . Observa-se que a adição de monensina na dieta não causou alterações nestas características $(\mathrm{P}>0,10)$, demonstrando médias de 3,54; 3,29 e 6,37 pontos, respectivamente. Já MENEZES et al. (2006) observaram comportamento quadrático para os valores de textura da carne de novilhos terminados em confinamento com a inclusão de 0,100 e $200 \mathrm{mg}$ de monensina animal $^{-1}$ $\mathrm{dia}^{-1}$ na dieta $(4,56 ; 3,28$ e 4,12 pontos, respectivamente). No estudo de RESTLE et al. (2000), os autores não verificaram alterações sobre as características de cor, textura e marmoreio quando foi adicionada à dieta de vacas de descarte $150 \mathrm{mg}$ de monensina animal ${ }^{-1} \mathrm{dia}^{-1}$.

Tabela 1 - Pontuação média obtida para cor, textura e marmoreio da carne de vacas de descarte terminadas em confinamento, de acordo com o nível de monensina sódica na dieta.

\begin{tabular}{|c|c|c|c|c|}
\hline \multirow{2}{*}{ Características } & \multicolumn{2}{|c|}{$\begin{array}{l}\text { Nível de monensina } \\
(\mathrm{mg} \text { animal }\end{array}$} & \multirow{2}{*}{$\mathrm{EP}^{1}$} & \multirow{2}{*}{$\mathrm{P}^{2}$} \\
\hline & 0 & 200 & & \\
\hline Cor & 3,67 & 3,42 & 0,24 & 0,4745 \\
\hline Textura & 3,33 & 3,25 & 0,22 & 0,7924 \\
\hline Marmoreio & 6,42 & 6,33 & 1,03 & 0,9550 \\
\hline
\end{tabular}

${ }^{1}$ Erro padrão das médias, sendo $\mathrm{n}=12$ por tratamento. ${ }^{2}$ Probabilidade.

Ciência Rural, v.36, n.5, set-out, 2006. 
Na tabela 2, observa-se que a inclusão da monensina na dieta afetou negativamente a palatabilidade da carne $(\mathrm{P}<0,10)$. MENEZES et al. (2006) demonstraram que a palatabilidade da carne de novilhos terminados em confinamento reduz com o aumento dos níveis de inclusão de monensina na dieta, devido à presença residual do aditivo na carne. Além disso, ao contrário do presente estudo, estes autores observaram que a presença deste tipo de ionóforo afetou negativamente a suculência e a textura da carne. Já na pesquisa de RESTLE et al. (2000), não foi observada alteração tanto para a palatabilidade como para a suculência da carne de vacas com a presença da monensina. Os valores médios de maciez, palatabilidade e suculência deste estudo foram semelhantes aos observados por KUSS et al. (2005) com animais mestiços da mesma categoria terminados em confinamento.

O perfil dos ácidos graxos do músculo Longissimus dorsi são apresentados na tabela 3. Os principais ácidos graxos encontrados na gordura intramuscular neste músculo, em ambos os tratamentos, foram os ácidos oléico (C18:1 n9c), palmítico (C16:0) e esteárico (C18:0), representando 90,4\% do total dos ácidos graxos. Resultados semelhantes também foram descritos por VARELA et al. (2004) e MENEZES et al. (2006). No presente estudo, observou-se que os ácidos oléico $(\mathrm{r}=0,55 ; \mathrm{P}=, 0058)$ e esteárico $(\mathrm{r}=0,48 ; \mathrm{P}=0,0177)$ estão positivamente associados com a marmorização da carne, ao passo que o palmítico apresentou associação negativa $(\mathrm{r}=-0,37 ; \mathrm{P}=0,0880)$.

Mesmo com participação pequena do ácido heptadecanóico (C17:0) na composição de ácidos graxos da carne dos animais, a adição da monensina na dieta aumentou $(\mathrm{P}<0,05)$ a sua participação. Padrão semelhante foi observado na pesquisa de EIFERT (2004), em que os autores verificaram maior participação do $\mathrm{C} 17: 0$ na gordura do leite quando adicionada monensina na dieta de vacas leiteiras. A monensina aumenta a proporção de propionato no rúmen, sendo que MANSBRIDGE \& BLAKE (1997) relatam que os ácidos graxos de cadeia ímpar constituem a maior participação dos lipídios microbianos, os quais são sintetizados com a utilização do propionato e do valerato. No entanto, o trabalho de MENEZES et al. (2006) apresentou valores inferiores e comportamento quadrático do C17:0 na carne de novilhos com o aumento do nível de monensina na dieta $(0,80 ; 0,76 \mathrm{e}$ $0,85 \%$ para os respectivos níveis 0,100 e $200 \mathrm{mg}$ $\left.\operatorname{animal}^{-1} \operatorname{dia}^{-1}\right)$.

Uma conseqüência negativa importante da adição da monensina na dieta dos animais é o incremento na participação do ácido elaídico (C18:1n9t) e a redução do ácido oléico (C18:1 n9c) na composição dos ácidos graxos totais. Isso porque as chamadas gorduras trans estão associadas a uma série de efeitos negativos à saúde humana. Os resultados do presente estudo parecem bastante consistentes e repetem uma tendência já descrita anteriormente (MENEZES et al., 2006), mesmo em trabalhos com vacas leiteiras (CANT et al., 1997 e SAUER et al., 1998). Segundo MANSBRIDGE \& BLAKE (1997), este ácido graxo é produto da biohidrogenação no rúmen dos ácidos graxos insaturados presentes na dieta.

LAWRIE (2005) relata que o sabor da carne é influenciado pela composição dos ácidos graxos da

Tabela 2 - Características organolépticas e sensoriais e da carne de vacas de descarte terminadas em confinamento, de acordo com o nível de monensina sódica na dieta.

\begin{tabular}{|c|c|c|c|c|}
\hline \multirow{2}{*}{ Características } & \multicolumn{2}{|c|}{ Nível de monensina (mg animal $\left.{ }^{-1} \operatorname{dia}^{-1}\right)$} & \multirow{2}{*}{$\mathrm{EP}^{1}$} & \multirow{2}{*}{$\mathrm{P}^{2}$} \\
\hline & 0 & 200 & & \\
\hline Quebra ao descongelamento, $\%$ & 10,42 & 10,51 & 0,76 & 0,9329 \\
\hline Quebra à cocção, \% & 22,03 & 21,93 & 1,71 & 0,9602 \\
\hline Shear, $\mathrm{kg}$ força $\mathrm{a}^{3}$ & 4,41 & 4,74 & 0,31 & 0,4690 \\
\hline Maciez, pontos & 5,92 & 5,61 & 0,21 & 0,3214 \\
\hline Palatabilidade, pontos & 6,75 & 6,08 & 0,27 & 0,0995 \\
\hline Suculência, pontos & 6,42 & 6,33 & 0,16 & 0,7192 \\
\hline Lipídios ${ }^{4}, \%$ & 2,82 & 2,63 & 0,29 & 0,6422 \\
\hline Proteína ${ }^{5}, \%$ & 75,78 & 75,85 & 0,85 & 0,9548 \\
\hline
\end{tabular}

${ }^{1}$ Erro padrão das médias, sendo $\mathrm{n}=12$ por tratamento.

${ }^{2}$ Probabilidade.

${ }^{3}$ Maiores valores indicam menor maciez.

${ }^{4} \mathrm{Na}$ matéria natural.

${ }^{5} \mathrm{Na}$ matéria seca. 
Tabela 3 - Perfil (\%) dos ácidos graxos do músculo Longissimus dorsi de vacas de descarte terminadas em confinamento, de acordo com o nível de monensina sódica na dieta.

\begin{tabular}{|c|c|c|c|c|}
\hline \multirow{2}{*}{ Ácidos graxos } & \multicolumn{2}{|c|}{ Nível de monensina (mg animal ${ }^{-1} \mathrm{dia}^{-1}$ ) } & \multirow{2}{*}{$\mathrm{EP}^{1}$} & \multirow{2}{*}{$\mathrm{P}^{2}$} \\
\hline & 0 & 200 & & \\
\hline C14:0 (Mirístico) & 2,90 & 3,27 & 0,16 & 0,1288 \\
\hline C14:1 (Meristoléico) & 0,43 & 0,37 & 0,04 & 0,2689 \\
\hline C15:0 (Pentadecanóico) & 0,21 & 0,25 & 0,04 & 0,4452 \\
\hline C16:0 (Palmítico) & 30,13 & 31,62 & 0,65 & 0,1217 \\
\hline C16:1 (Palmitiléico) & 2,89 & 2,98 & 0,09 & 0,4817 \\
\hline C17:0 (Heptadecanóico) & 0,87 & 1,05 & 0,04 & 0,0024 \\
\hline C17:1 (Cis-10-Heptadecanóico) & 0,47 & 0,50 & 0,02 & 0,4548 \\
\hline C18:0 (Esteárico) & 19,32 & 19,47 & 0,59 & 0,8584 \\
\hline C18:1 n9t (Elaídico) & 0,11 & 1,07 & 0,15 & 0,0002 \\
\hline C18:1 n9c (Oléico) & 40,95 & 37,59 & 0,92 & 0,0175 \\
\hline C18:2 n6c (Linoléico) & 1,39 & 1,43 & 0,10 & 0,7647 \\
\hline C20:4 n6 (Araquidônio) & 0,33 & 0,42 & 0,04 & 0,1363 \\
\hline Saturados & 53,42 & 55,65 & 0,88 & 0,0886 \\
\hline Insaturados & 46,58 & 44,37 & 0,89 & 0,0919 \\
\hline Monoinsaturados & 44,86 & 42,52 & 0,88 & 0,0755 \\
\hline Poliinsaturados & 1,72 & 1,85 & 0,12 & 0,4698 \\
\hline Poliinsaturado: Saturado & 0,03 & 0,03 & 0,002 & 0,7634 \\
\hline
\end{tabular}

${ }^{1}$ Erro padrão das médias, sendo $\mathrm{n}=12$ por tratamento.

${ }^{2}$ Probabilidade.

fração lipídica da carne. Diferente do que foi relatado por WALDMAN et al. (1968), os ácidos graxos mirístico $(\mathrm{r}=-0,11 ; \mathrm{P}=0,6071)$ e palmítico $(\mathrm{r}=-0,07 ; \mathrm{P}=$ $0,7297)$ não apresentaram associação negativa significativa com a suculência da carne das vacas. Por outro lado, os ácidos elaídico $(\mathrm{r}=0,45 ; \mathrm{P}=0,0275)$, oléico $(\mathrm{r}=0,47 ; \mathrm{P}=0,0189)$ e o total de ácidos insaturados $(\mathrm{r}=$ 0,$39 ; \mathrm{P}=0,0622$ ) demonstraram associação positiva com o sabor da carne.

Verifica-se, neste estudo, que o total de ácidos graxos saturados e insaturados aumentaram e diminuíram, respectivamente. Isso demonstra que a adição deste ionóforo potencializa a biohidrogenização dos ácidos graxos presentes na dieta pelos microorganismos ruminais.

\section{CONCLUSÕES}

A monensina diminuiu a qualidade da carne das vacas por diminuir a palatabilidade e alterar negativamente o perfil de ácidos graxos, proporcionando maior participação de ácidos graxos saturados em detrimento dos insaturados e também incrementando a participação de ácidos graxos trans no perfil de ácidos graxos da gordura intramuscular do músculo Longissimus dorsi.

\section{REFERÊNCIAS}

ANUALPEC. Anuário estatístico da produção animal. FNP. São Paulo: Camargo Soares, 2005. 400p.

CANT, J.P. et al. Effect of fish oil on milk composition in dairy cows. Canadian Journal of Animal Science, v.77, p.125-131, 1997.

EIFERT, E.C. Fontes de carboidratos, óleo de soja e monensina para vacas lactantes: desempenho, digestibilidade, parâmetros ruminais e perfil de ácidos graxos do leite. 2004. 117f. Tese (Doutorado em Zootecnia) - Universidade Federal de Viçosa.

FELLNER, V. et al. Effect of nigericin, monensin, and tetronasin on biohydrogenation in continuous flow-trough ruminal fermentors. Journal of Dairy Science, v.78, p.18151823, 1997.

FOLCH, J. et al. A simple method for the isolation and purification of total lipids from animal tissues. Journal Biological Chemical, v.226, p.497-509, 1957.

KUSS, et al. Composição física da carcaça e qualidade da carne de vacas de descarte de diferentes grupos genéticos terminadas em confinamento com distintos pesos. Revista Brasileira de Zootecnia, v.34, n.4, p.1285-1296, 2005.

LAWRIE, R.A. Ciência da carne. 6.ed. Artmed: Porto Alegre-RS, 2005. 384p.

MANSBRIDGE, R.J.; BLAKE, J.S. Nutritional factors affecting the fatty acid composition of bovine milk. British Journal of Nutrition, v.78, suppl.1, p.S37-S47, 1997.

Ciência Rural, v.36, n.5, set-out, 2006. 
MENEZES, L.F.G. et al. Perfil de ácidos graxos de cadeia longa e qualidade da carne de novilhos terminados em confinamento com diferentes níveis de monensina sódica na dieta. Ciência Rural, v.36, n.1, p.186-190, 2006.

MÜllER, L. Normas para avaliação de carcaças e concurso de carcaça de novilhos. 2.ed. Santa Maria: UFSM, 1987. 31p.

NRC - NATIONAL RESEARCH COUNCIL. Nutrient requeriments of beef cattle. 7. rev ed. Washington: National Academy, 1996. 242p.

RESTLE, J. et al. Efeito da monensina sódica sobre a composição física e características qualitativas da carcaça e da carne de novilhas. In: REUINIÃO ANUAL DA SOCIEDADE BRASILEIRA DE ZOOTECNIA, 37., Viçosa. Anais... Viçosa: SBZ/Gmosis, [2000]. CD ROM.

SAS INSTITUTE. SAS/STAT user's guide: statistics. 8.ed Verson 6.11, Cary, 1997. V.6, 943p.

SAUER, F.D. et al. Methane output and lactation response in Holstein cattle with monensina or unsaturated fat added to the diet. Journal of Animal Science, v.76, p.906-914, 1998.
SIMOPOULOS, A.P. Essential fatty acids in health and chronic disease. American Journal Clinic and Nutrition, v.70, Suppl, p.560-569, 1999.

TERRA, N.N.; BRUM, M.A.R. Carne e seus derivados. Técnicas de controle de qualidade. São Paulo: Nobel, 1998. 121p.

VAN NEVEL, C.J.; DEMEYER, D.I. Lipólysis and biohidrogenation of soybean oil in the rumen in vitro: Inhibition by antimicrobials. Journal of Dairy Science, v.78, p.27972806, 1995.

VARELA, A. et al. Effect of pasture finishing on the meat characteristics and intramuscular fatty acid profile of steers of the Rubia Gallega breed. Meat Science, v.67, p.5515-522, 2004 .

WALDMAN, R.C. et al. Fatty acids of certain bovine tissue and their association with growth, carcass and palatability traits. Journal of Animal Science, v.27, n.1, p.628-631, 1968.

WOOD, J.D. et al. Effects of fatty acids on meat quality: a review. Meat Science, v.66, p.21-32, 2003. 